\title{
Mobilidade, compadrio e clientela no Antigo Regime: interações entre escravas, forras e elites na Comarca de Vila Rica, século XVIII ${ }^{1}$
}

Mobility, crony and clientelism in the Ancien Regime: interactions between slaves, freedmen and elites in the District of Vila Rica, XVIII century

Ana Paula Pereira da Costa*

Universidade Federal de Juiz de Fora (UFJF), Juiz de Fora, MG, Brasil

\begin{abstract}
RESUMO: Neste artigo busca-se apresentar algumas reflexões sobre a construção de redes clientelares feitas entre a elite local da comarca de Vila Rica na primeira metade do século XVIII com escravas e forras estabelecidas através do amadrinhamento que teciam com os cativos (adultos e crianças) pertencentes aos membros dessa elite. Tomaremos como estudo de caso a escravaria do mestre de campo Antônio Ramos dos Reis, homem de destacado poder econômico e político na região. Pretende-se ainda revelar como as redes clientelares intermediadas pelo compadrio proporcionavam a essas mulheres escravas e forras alcançar elementos considerados pela historiografia mais recente sobre o período colonial brasileiro como fulcrais para se pensar perspectivas de mobilidade social (não só econômica, mas também social) entre os grupos subalternos em uma sociedade escravista e de Antigo Regime.
\end{abstract}

PALAVRAS-CHAVE: Compadrio. Mobilidade Social. Escravas. Forras. Elites Coloniais.

ABSTRACT: This article present some thoughts about building clientelism networks made by slaves and freedwomen with the local elite, the district of Vila Rica in the first half of the XVIII century, through the amadrinhamento of slaves (adults and children) this elite, highlighting if, to illustrate the arguments, the case of the master of the field Antonio Ramos dos Reis. Another objective is to reveal how the clientelism networks mediated at crony gave these women elements considered by the latest historiography on the colonial period as keys to think about social mobility prospects (not only economic but also social) between subaltern groups in a slave society and of Ancien Regime.

KEYWORDS: Crony. Social Mobility. Slaves. Freedmen. Colonial Elites.

\footnotetext{
* Professora Adjunta da Universidade Federal de Juiz de Fora (UFJF). Doutora em História Social pela Universidade Federal do Rio de Janeiro (UFRJ). E-mail: anappcosta@ig.com.br. Orcid: https://orcid.org/0000-0002-8008-1650.
} 


\section{Introdução}

O texto busca apresentar algumas reflexões sobre a construção de redes clientelares feitas entre a elite local da comarca de Vila Rica na primeira metade do século XVIII com escravas e forras estabelecidas através do amadrinhamento que teciam com os cativos (adultos e crianças) pertencentes aos membros dessa elite. Tomaremos como estudo de caso a escravaria do mestre de campo Antônio Ramos dos Reis, homem de destacado poder econômico e político na região. Recentemente a historiografia tem destacado o compadrio e a formação de redes clientelares como importantes mecanismos de hierarquização e alcance de distinções sociais para africanos e seus descendentes (escravos, forros e livres) que viveram no período colonial brasileiro. Os trabalhos que analisam as relações em uma sociedade escravista por esse viés destacam que, na construção de tais redes de relações clientelares, pesava grandemente a linguagem da dependência pessoal e do parentesco ritual, pois eram elementos de uma linguagem conhecida dos escravos (africanos e crioulos), de forros e de livres - inclusive de membros da elite colonial.

Assim, neste trabalho objetiva-se revelar como as redes clientelares intermediadas pelo compadrio proporcionavam a mulheres escravas e forras alcançar elementos que têm sido considerados como fulcrais para se pensar perspectivas de mobilidade social (não só econômica, mas também social) entre os grupos subalternos em uma sociedade escravista e de Antigo Regime.

\section{Alguns apontamentos teóricos}

Pensar as possibilidades de melhoras nas condições de vida e ascensão econômica entre os africanos e seus descendentes, homens e mulheres, na sociedade colonial brasileira não é algo novo. No que tange às mulheres, em termos gerais, até a década de 1970, a historiografia no período colonial, com foco nas escravas e forras, era pautada por uma visão que realçava a percepção da mulher enquanto objeto de dominação sexual masculina, enfatizando as atividades de prostituição, a submissão, a acomodação e a passividade diante da realidade posta. Em oposição a essas análises historiográficas, a partir dos anos de 1980 o papel social e histórico das mulheres no período colonial, em especial as pertencentes aos grupos mencionados, passou a ser revisto, destacando especialmente suas respectivas atuações e contribuiçóes para a organização social e econômica da América portuguesa e suas possibilidades de enriquecimento, sobretudo entre o segmento forro ${ }^{2}$.

Dentre as atividades que possibilitavam ascensão econômica para as mulheres escravas e forras no período colonial, ganhou destaque o papel do comércio (ambulante e fixo, de alimentos, bebidas e adornos - dentre os quais os amuletos mágicos) como um importante meio de sustento para muitas delas. Para as forras, tal atividade foi encarada como meio de aquisição de bens para melhor sobrevivência (escravos, instrumentos de trabalho, roupas, joias). Já para as escravas, a atuação no comércio foi analisada como possibilidade de acumular algum pecúlio para a compra da almejada liberdade. Além do comércio, o desempenho de outras atividades é tido como possibilitador de ascensão econômica, tais como costureiras, doceiras, fiandeiras e rendeiras, além de ocupações tradicionalmente femininas como as de cozinheira, lavadeira, criada e parteira ${ }^{3}$. Atividades como a mineração, embora notadamente de cunho masculino, também aparecem em vários documentos do século XVIII sendo exercida por mulheres. Segundo Eduardo França Paiva (2002, p. 2-3), mulheres negras e mestiças sempre estiveram intimamente ligadas às áreas de mineração e à população de mineradores, pois transportaram para a América portuguesa culturas e técnicas de minerar. 
Os argumentos acima denotam mecanismos de mobilidade econômica para mulheres, cativas, forras e também livres, que se efetivavam à medida que elas iam se ajustando à sociedade colonial e iam adquirindo algum cabedal. Todavia, a partir de uma discussão voltada para a análise da colônia sob perspectiva revisionista, tem-se buscado aprimorar o entendimento das formas de mobilidade, não só econômica, mas também social, e a hierarquização no seio dos grupos subalternos, dentre os quais se incluem as mulheres (escravas, forras e livres).

A crítica elaborada por Rober to Guedes e Márcio Soares (2014) resume bem um dos pontos fortes do debate. Para os referidos autores, o fato de os escravos e os libertos ocuparem os patamares inferiores da sociedade na América portuguesa, somada a ênfase muito grande às restriçóes de ordem legal que a Coroa lusitana tentava impor às pessoas não brancas, fez com que alguns estudiosos descuidassem da análise das hierarquias, da mobilidade e do prestígio social desses segmentos. Logo, pensa-se nos entraves impostos à ascensão e nas enormes distâncias entre o topo e a base da pirâmide social, para, peremptoriamente, concluir pela ínfima chance de mobilidade e pela total ausência de prestígio daqueles indivíduos alocados nos estratos mais baixos do corpo social. Desconsidera-se que se, por um lado, a passagem de um estrato social para outro era, de fato, difícil e restrita, por outro havia a possibilidade de mudança de posição social no interior do segmento em que o indivíduo se situava. Afinal, era a busca de distinção entre iguais que frequentemente comandava as aspirações de estima social. Na visão desses historiadores, embora as pesquisas tenham avançado no sentido de demonstrar a capacidade de uma expressiva acumulação de bens por parte de alguns ex-escravos e seus descendentes, seus autores não reconheciam a conquista de prestígio social no seio da ordem escravocrata, salvo em casos excepcionais. Concordamos com os argumentos de Guedes e Soares (2014), sobretudo a defesa de que o princípio da hierarquização, que naturalizava as desigualdades entre os membros do corpo social, estava presente em todos os estratos daquela sociedade, dos escravos à nobreza da terra. Assim como nos patamares mais elevados da pirâmide social havia nobres mais nobres do que outros, nas faixas intermédias havia forros e forros, e na base havia escravos e escravos. Por conseguinte, em uma sociedade em que praticamente tudo distinguia e hierarquizava, é licito supor que certas qualidades e condições alcançadas por alguns escravos, forros e livres deviam fazer uma sensível diferença entre os seus pares e para aqueles que permaneciam em posições inferiores (GUEDES; SOARES, 2014, p. 576-577). Conforme apontam os referidos autores:

Como costumava acontecer nas sociedades de Antigo Regime, nem sempre a riqueza era fator determinante para a obtenção de prestígio. Estabelecer relações de clientela, na condição de subalterno, com gente graúda também era coisa de valor, pois promovia distinções. É importante frisar que a busca de distinção social feita por escravos, forros e livres (mulatos e pardos inclusive) estava endereçada mais aos seus iguais ou aos de status inferior do que àqueles situados nas camadas sociais mais elevadas. Ou seja, as aspiraçóes se restringiam ao interior do grupo ou ao estamento a que pertenciam. É lícito assim pensar que dificilmente um liberto que vivesse como artesão almejaria se tornar um dos principais da terra e exercesse, por exemplo, as funções e dignidades de um guarda-mor. Mas ele podia desejar e envidar esforços para alcançar a condição de mestre de seu ofício e, assim, se diferenciar dos demais, digamos, carpinteiros, e gozar de prestígio entre seus pares por conta disso. A ideia era se afastar de todos os modos possíveis das marcas do cativeiro, apagar a desonra da escravidão, se distinguirem ante seus pares e outros grupos sociais com os quais conviviam. Pensar mobilidade social entre os subalternos nestes termos torna-se muito mais dinâmico e complexo (GUEDES; SOARES, 2014, p. 578, grifo dos autores). 
Sob esse viés, relativa importância tem sido dada ao compadrio para auxiliar os subalternos em expectativas e possibilidades de ascensão, sendo dado maior destaque, embora ainda de forma incipiente, às figuras femininas nesse cenário. Afinal, em muitos setores, a dinâmica social e cultural das áreas urbanas e rurais da América portuguesa era marcada pela atuação feminina negra e mestiça, escrava, livre e liberta. Estudos apontam que, se no grupo de escravos e livres o elemento masculino prevaleceu na capitania mineira, entre o segmento forro destacam-se numericamente as mulheres (PAIVA, 2002, p. 10).

A historiografia considera já há algum tempo, como demonstrou o estudo clássico de Gudeman e Schwartz (1988), por exemplo, que as relações desenvolvidas via compadrio possibilitavam aos chamados estratos subalternos da América portuguesa (homens e mulheres, indígenas, escravos, forros, livres pobres, etc.) melhorias em suas condições de vida, apesar de estarem inseridos num contexto social desigual no qual tais possibilidades eram limitadas. Para mulheres escravas, o compadrio foi encarado como recurso utilizado para tentar garantir a liberdade de seus filhos. Para as forras e livres, podiam auxiliar no estreitamento dos laços de convivência no seu cotidiano. Essas relações asseguraram o socorro mútuo necessário, diante das inúmeras dificuldades pelas quais passavam (GUDEMAN; SCHWARTZ, 1988, passim).

Em vários estudos, a relevância do batismo foi realçada por se tratar de um mecanismo de conquista de aparentados e aliados, instituindo um rito que sancionava formalmente uma aliança forjada anteriormente. Assim, formavam-se alianças desejadas por pais e padrinhos, estendida a uma terceira parte, batizando-a (ENGEMANN, 2005, p. 189). Nas palavras de Manolo Florentino e José Roberto Góes (1997, p. 91-92):

O compadrio é uma relação parental de base espiritual, mas nem por isso menos importante do que aquelas de outros tipos, como as de base consanguínea ou o parentesco por meio de alianças matrimoniais, sobretudo no âmbito de uma sociedade em que o cristianismo a tudo plasma.

Para Cacilda Machado, que analisou as relações de compadrio entre escravos e libertos na Vila de São José dos Pinhais em fins do século XVII, o batismo foi utilizado enquanto estratégia de proteção social, formação e consolidação de uma comunidade de escravos e libertos de cor, assim como estreitava as relações entre estes grupos e os indivíduos brancos (MACHADO, 2006, p 49-77).

Analisando batismos de escravos em Vila Rica no século XVIII, Donald Ramos destaca que, para eles, o compadrio tinha a mesma função exercida pelas irmandades, ou seja, criar espaços de convívio nos quais os escravos podiam manter sua cultura, estimulando a formação de lideranças próprias dentro de uma estrutura luso-brasileira aceitável (RAMOS, 2004, p. 54).

Ainda no contexto mineiro, Silvia Brügger aponta que o compadrio era uma importante ferramenta responsável pela extensão dos laços sociais firmados entre indivíduos de diferentes grupos sociais. $\mathrm{O}$ apadrinhamento permitia que homens e mulheres, adultos e crianças, das mais diferentes condições sociais, passassem a se reconhecer como parentes. Segundo a autora, o batismo, diferentemente das alianças matrimoniais, não possuía qualquer implicação de ordem patrimonial. Assim, embora o afilhado almejasse ser beneficiado futuramente, não necessariamente estaria incluído na partilha dos bens (BRÜGGER, 2007, passim). Desse modo, o parentesco fictício possibilitava que indivíduos pertencentes a diferentes grupos sociais se reconhecessem como "parentes" sem que houvesse ameaça ao patrimônio familiar(VENÂNCIO, 2003, p. 598). Não por acaso, o batismo cristão mostrou-se no 
âmbito da sociedade brasileira como uma instituição forte e almejada por todos os estratos da população, significando a entrada do pagão no seio da Igreja Católica (FREIRE, 2004, p. 2).

Outros trabalhos têm revelado que o batismo permite compreender o funcionamento das relações políticas e sociais em um cenário de Antigo Regime. Podia ser utilizado para reforçar laços de parentesco já existentes, desenvolver relações com semelhantes ou mesmo com indivíduos socialmente desiguais. Por meio do compadrio, as relaçôes hierarquizadas de Antigo Regime reproduziam-se: de um lado o padrinho e do outro a família e o afilhado, hierarquicamente posicionados. Os vínculos e as proximidades que o parentesco ritual reforçava se tornavam especiais e carregados de valor simbólico (MAIA, 2008, p. 18). As diferenças de estatuto jurídico não impediram na sociedade lusa, estamental e escravista, que as pessoas mantivessem relações de parentesco ritual ou de afinidade (FRAGOSO; GUEDES; SAMPAIO, 2014, p. 11).

De acordo com Thiago Krause, nas sociedades católicas do mundo luso, o compadrio deve ter atuado desde o início da formação dessa sociedade escravista como forma de interação, servindo como primeiro mecanismo a ligar institucionalmente cativos e livres. Sendo assim, por meio dos laços firmados por parentesco espiritual, desenvolvido a partir do compadrio, indivíduos pertencentes a diferentes grupos sociais (livres, forros, escravos) poderiam utilizar-se desse vínculo enquanto estratégia de sobrevivência e/ou para aquisição de ganhos materiais ou imateriais (amizade, solidariedade, convivência). Esses laços foram favorecidos pelo contexto da época, uma sociedade permeada por noções de Antigo Regime, na qual o prestígio, a distinção, e a desigualdade eram seus pilares (KRAUSE, 2014, p. 292).

Outro exemplo temos com o estudo de João Fragoso acerca das relaçóes desenvolvidas via compadrio na localidade do Rio de Janeiro na primeira metade do século XVIII. Neste trabalho, analisou a parentela de forras com homens da elite, na qual aparecem como madrinhas/parceiras de nobres em cerimônias de batismos. $\mathrm{O}$ autor investigou também as relações desenvolvidas entre cativos e a elite por meio do batismo e denominou o grupo como "elite das senzalas", demonstrando que havia distinção/prestígio no universo das senzalas para aqueles cativos que de alguma forma teciam relações de afinidade com a casa grande devido às redes de compadrio. Segundo João Fragoso, no mesmo processo em que nobreza, via compadrio, organizava a sociedade, ela gerava também alianças hierárquicas com escravos e forros. Sendo assim, por meio das normas de Antigo Regime, as forras adquiriam ferramentas conceituais para criar redes sociais e implementar estratégias que contemplassem seus interesses. Nessa perspectiva, as redes de sociabilidade desenvolvidas pelas forras se tornariam, possivelmente, um recurso para alcançarem melhores patamares na estratificação social local (FRAGOSO, 2014a, p. 268). Ou seja, a partir de problematizações como essa, tem-se aventado a possibilidade de setores ligados aos estratos subalternos terem desenvolvido práticas parentais e redes clientelares, não só entre si, mas com membros da elite, que permitiam, em alguma medida, mobilidade social no sentido de adquirir distinções e status, elementos mais substanciais em um universo de Antigo Regime do que a riqueza material ${ }^{4}$.

A noção de redes clientelares utilizada para embasar a reflexão proposta é encarada como um mecanismo informal de constituição do poder dos grupos de elite da sociedade colonial e componente estratégico nas ações dos chamados estratos subalternos. Assim sendo, entende-se que, no contexto colonial brasileiro, a formação das redes clientelares (ou verticais), isto é, alianças tecidas entre elites com lavradores, libertos, escravos indígenas e africanos (FRAGOSO, 2006, 
p. 5) cimentavam as relaçóes sociais, configurando uma espiral que estruturava as relaçóes de poder de alto a baixo, ou seja, desde os grupos subalternos até o Rei.

Conforme aponta José Maria Imízcoz Beunza, as sociedades de Antigo Regime compreendiam um complexo conjunto de corpos sociais, vínculos pessoais e redes sociais. Os vínculos, como o parentesco, amizade e clientela, eram utilizados como elementos de distinção e na conformação de amplas redes de poder. Essas redes congregavam homens e mulheres de diferentes grupos sociais que se utilizavam dessas ligaçóes como elementos fundamentais na busca por capital social, demonstrando a habilidade que alguns indivíduos possuíam de empreender estratégias e mobilizar ações em busca dos seus interesses (BEUNZA, 1996, passim). Em geral, tais vínculos não resultavam de livres adesões e eram desiguais, já vinham dados pelo nascimento ou eram adquiridos através de outras vias de pertencimento, como os vínculos de amizade e a clientela. Os termos dessas relaçóes eram preestabelecidos, anteriores ao sujeito e impunha-se a ele de maneira imperante. Tais vínculos comportavam um alto grau de dependência. A dependência dava-se no âmbito dos costumes, das normas e obrigaçôes que regiam as comunidades e grupos a que os indivíduos pertenciam (BEUNZA, 1996, p. 23). O indivíduo estava fortemente submetido à sua própria comunidade, às regras da casa, dos deveres de reciprocidade, das obrigaçóes de parentesco, de vizinhança, de paróquia, ou de qualquer sociedade de que fazia parte. Como toda relação entre desiguais, esses vínculos comportavam posição de autoridade e exigiam uma subordinação (Ibid., p. 27).

Já Ângela Barreto Xavier e Antônio Manuel Hespanha assinalam que esses vínculos sociais comportavam uma economia política de favores de dom e contra dom, constituindo-se em reciprocidade social entre desiguais. Conforme estes autores:

A comunicação pelo dom introduzia o benfeitor e o beneficiado numa economia de favores. Estes eram de natureza diversa e variavam consoante a posição dos actores nos vários planos do espaço social (e correlativa posse de capital econômico, político, simbólico), [...] o que provocava um contínuo reforço económico e afectivo dos laços que uniam, no início, os actores, numa crescente espiral de poder, subordinada a uma estratégia de ganhos simbólicos, que se estruturava sobre os actos de gratidão e serviço (XAVIER; HESPANHA, 1998, p. 340).

O dom fundamenta-se num ato de favor, prestado por aqueles detentores de recursos para seus dependentes. A atividade de dar (a liberalidade, a graça) integrava uma tríade de obrigaçóes: dar, receber e retribuir. Essa triagem era responsável por consolidar as relações de poder de uma dada sociedade baseada em um modelo de trocas entre indivíduos hierarquicamente situados em posições desiguais (XAVIER; HESPANHA, 1998, p. 340).

No âmbito da historiografia brasileira, João Fragoso e Maria de Fátima Gouvêa, por exemplo, definem o conceito de rede como network de relacionamentos constituídas a partir das ações e das relações entre indivíduos que possuíam acessos a informações e recursos diferenciados entre si (FRAGOSO; GOUVÊA, 2010, p. 23). Desse modo, direitos, obrigaçóes e troca de favores regiam o funcionamento e articulavam as redes de sociabilidades e clientelas em sociedades estruturadas por normas de Antigo Regime.

Já Cacilda Machado define rede clientelar como um complexo sistema relacional que permite a circulação de bens e serviços, tanto materiais como imateriais, dentro de um conjunto de relações estabelecidas entre seus membros, que os afeta a todos, direta ou indiretamente, ainda que de maneira desigual. Como a rede social é uma ferramenta capaz de tornar mais evidente 
as interações entre os indivíduos e os contextos sociais em que se encontram e atuam, a análise deixa de priorizar a estrutura social em si, para privilegiar os processos e as interações no interior da sociedade estudada. Cabe sublinhar que a reprodução desta sociedade se fundamentava na dependência interpessoal - entendendo-se este último conceito como o conjunto de laços unindo membros de diferentes grupos, laços originados na própria ação dos sujeitos sociais, de acordo com suas necessidades, seus interesses e suas possibilidades (MACHADO, 2008, p. 18-20).

Considerando que redes clientelares estruturavam os vários níveis de interação social e os comportamentos cotidianos das pessoas na sociedade abordada, estudos sobre as redes de compadrio desenvolvidas por grupos subalternos são importantes para percebermos as estratégias desenvolvidas por esses indivíduos para conquistarem melhores patamares na estratificação social.

Do ponto de vista dos escravos e forros, a inserção em redes clientelares, além de proporcionar ganhos concretos e melhoras nas suas condiçóes de vida, revela o papel ativo que possuíam no processo de produção e reprodução de uma sociedade escravista, pois se entende que os comportamentos de tais grupos, baseados em negociações e reciprocidades desiguais, não seriam expressão da adesão passiva ao ideário senhorial. Elas talvez tenham sido os meios mais à mão para que pudessem reiterar sua humanidade e tornar a si próprios participantes da construção de suas histórias. A dependência e a submissão não devem ser entendidas apenas de forma unilateral, sendo preciso atentar para o interesse do dependente pela dependência, do submisso pela submissão. Podem ser estratégias, uma maneira de tentar aumentar a segurança em meio aos recursos disponíveis e às incertezas dos intentos (MACHADO, 2008, p. 22; p. 54-55).

Obviamente que não se desconsidera a existência do uso de coerção e força sobre a parcela da população escravizada e forra, de africanos e seus descendentes. Tão pouco, ao adotar-se a ideia de negociação e reciprocidade entre os atores na construção das redes de relações clientelares, o conflito e as tensões inerentes a tais interações são negligenciados. Pelo contrário, ao se falar em tais termos, necessariamente considera-se que eles eram desiguais e que reforçavam hierarquias. Se este era um universo que se desenvolvia sob laços de dependência pessoal/clientelar é sempre bom lembrar que se tratava de laços que uniam membros de diferentes grupos e que se originavam da própria ação dos sujeitos sociais, de acordo com suas necessidades, seus interesses e suas possibilidades. A problemática em destaque vem sendo analisada pela historiografia colonial brasileira há relativamente pouco tempo 5 e, embora se tenha avançado no conhecimento deste crucial ponto, ainda há muito a ser investigado.

\section{A escravaria do mestre de campo Antônio Ramos dos Reis}

Antônio Ramos dos Reis foi um dos homens mais renomados da região da Comarca de Vila Rica. Natural do Porto, ao migrar para a América portuguesa estabeleceu-se inicialmente no Rio de Janeiro atuando no posto de soldado infante. Com a descoberta do ouro em Minas Gerais, dirigiu-se para a capitania por volta de $1714^{6}$. No território mineiro, estabeleceu uma trajetória de sucesso ocupando vários postos militares de destaque como o de capitão de auxiliares no distrito de São Bartolomeu, o de mestre de campo de Vila Rica em 1732, localidade na qual se fixou, e, em 1741, o de capitão-mor das ordenanças de Vila Rica (FRANCO, 1989, p. 336)7. Além da ocupação de importantes postos militares, exerceu relevantes cargos, como o de vereador em 1719, juiz ordinário em 1739,1745 e $1757^{8}$ e foi cotado para ser juiz de órfãos em $1732^{9}$, todos em Vila 
Rica, sendo ainda contemplado com o hábito da Ordem de Cristo ${ }^{10}$. Em várias ocasióes, atuou em prol da Coroa lusitana e das autoridades que a representavam no ultramar para a efetivação da governabilidade no território colonial sempre à custa de sua vida, fazenda e escravos armados.

Além dos postos e cargos que lhe conferiam enorme prestígio e atestavam sua qualidade social, este poderoso local foi também um dos homens mais abastados das Minas Gerais. Foi descobridor de uma grandiosa lavra "localizada no morro chamado comumente de morro do Ramos onde tem serviço de talho aberto e várias minas com muitas grades, tanques de recolher águas, onde tem para cima de 100 escravos"11. Possuía uma fortuna estimada, no fim de sua vida, em 78:000\$000 contos de réis (ALMEIDA, 2001, p. 260). Infelizmente não conseguimos encontrar o inventário de Antônio Ramos dos Reis para conhecermos a totalidade de seu plantel no momento final de sua vida. De todo modo, através dos registros paroquiais, podemos ter uma dimensão parcial da quantidade de escravos que possuía e da configuração de sua escravaria.

Entre 1727 e 1748, levou à pia batismal, como proprietário, nada menos que 59 cativos, sendo 32 adultos e 27 crianças $^{12}$. Desses 32 adultos 26 eram homens e 6 eram mulheres.

Tabela 1 - Padrinhos e madrinhas dos escravos adultos do mestre de campo Antônio Ramos dos Reis, 1727-1748

\begin{tabular}{|c|c|c|c|c|c|c|c|c|}
\hline \multirow{2}{*}{} & \multicolumn{2}{|c|}{ Escravos } & \multicolumn{2}{c|}{ Forros } & \multicolumn{2}{c|}{ Sem informação } & \multicolumn{2}{c|}{ Total } \\
\cline { 2 - 9 } & $\#$ & $\%$ & $\#$ & $\%$ & $\#$ & $\%$ & $\#$ & $\%$ \\
\hline Padrinhos & 23 & 88,46 & - & - & 3 & 11,54 & 26 & 100 \\
\hline Madrinhas & 15 & 57,69 & 7 & 26,92 & 4 & 15,38 & 26 & 100 \\
\hline
\end{tabular}

Fonte: Arquivo Eclesiástico da Arquidiocese de Mariana (AEAM): Livros de batismos de escravos de Mariana e seu termo. Registros Paroquiais de Batismos, livros O-03 e T-01. Arquivo da Casa dos Contos (ACC): Registros Paroquiais de Batismos, rolo 027, volume 491 e 493; rolo 104, volume 492, período de 1711 a 1750.

Os dados revelam que os escravos adultos do plantel do mestre de campo Antônio Ramos dos Reis teceram, em sua maioria, relações com outros companheiros de cativeiro. Mais especificamente, os homens escravos foram acompanhados no batismo por 23 padrinhos com o mesmo status social, sendo 22 pertencentes ao referido poderoso local e 1 deles pertencente ao plantel de Domingos Gonçalves. Nos outros três casos não conseguimos identificar a condição social dos padrinhos. E dentre esses padrinhos escravos pertencentes ao plantel de Antônio Ramos não houve grande variedade ou rotatividade na escolha deles, pois o escravo Manoel apadrinhou oito cativos recém-chegados, o escravo Bento apadrinhou três cativos recém-chegados, o escravo Mathias apadrinhou três, o escravo Antônio também apadrinhou três, o escravo Francisco apadrinhou dois e o escravo Ventura apadrinhou dois escravos, havendo ainda batismo individual feito pelo escravo Salvador. Ou seja, dentre toda a escravaria de Antônio Ramos, apenas sete de seus cativos apadrinharam escravos recém-chegados.

Acerca das madrinhas desses 26 escravos homens recém-chegados, o padrão repete-se, pois, a grande maioria era também composta por escravas. Havia assim 15 madrinhas de mesmo estatuto social, 7 forras, um caso de batismo sem presença de madrinha e três casos nos quais não conseguimos estabelecer a condição social da mesma. Dentre as 15 madrinhas escravas, 9 pertenciam ao plantel do Antônio Ramos e 6 a outros senhores. Dos 9 casos de madrinhas escravas temos Graça 
Ramos, Domingas e Joanna amadrinhando duas vezes. As escravas Maria, Inácia e Sebastiana Ramos fizeram-no uma vez. Das 6 escravas pertencentes a outros senhores que amadrinharam no plantel de Antônio Ramos, a escrava Luiza pertencente a João da Cunha foi escolhida duas vezes para tal fim, o mesmo ocorrendo com a escrava Mariana pertencente à Micaela Ramos, ex-escrava de Antônio Ramos dos Reis. Nos outros dois casos, temos a escrava Joana pertencente a João Pereira e a escrava Thereza pertencente a Domingos Rodrigues amadrinhando uma vez neste plantel. Com relação às forras, Joana Marques foi escolhida cinco vezes para amadrinhar escravos homens recém-chegados de Antônio Ramos. As forras Joanna e Maria amadrinharam uma vez neste plantel.

Tabela 2 - Padrinhos e madrinhas das escravas adultas do mestre de campo Antônio Ramos dos Reis, $1727-1748$

\begin{tabular}{|l|c|c|c|c|c|c|c|c|}
\hline & \multicolumn{2}{|c|}{ Escravos } & \multicolumn{2}{c|}{ Forros } & \multicolumn{2}{c|}{ Sem informação } & \multicolumn{2}{c|}{ Total } \\
\cline { 2 - 9 } & $\#$ & $\%$ & $\#$ & $\%$ & $\#$ & $\%$ & $\#$ & $\%$ \\
\hline Padrinhos & 5 & 83,33 & - & - & 1 & 16,67 & 6 & 100 \\
\hline Madrinhas & 3 & 50 & 2 & 33,33 & 1 & 16,67 & 6 & 100 \\
\hline
\end{tabular}

Fonte: Arquivo Eclesiástico da Arquidiocese de Mariana (AEAM): Livros de batismos de escravos de Mariana e seu termo. Registros Paroquiais de Batismos, livros 0-03 e T-01. Arquivo da Casa dos Contos (ACC): Registros Paroquiais de Batismos, rolo 027, volume 491 e 493; rolo 104, volume 492, período de 1711 a 1750.

Com relação às seis mulheres recém-chegadas, no que tange aos padrinhos havia cinco escravos e um que não conseguimos identificar a sua condição jurídica. Dos cinco escravos, quatro eram de Antônio Ramos e um de outro senhor, no caso, Fernando Gonçalves. Dos quatro escravos de Antônio Ramos que apadrinharam mulheres recém-chegadas, o escravo Bento fê-lo por duas vezes, o escravo Manoel e o escravo Antônio fizeram-no uma vez, lembrando que esses mesmos três escravos já haviam sido escolhidos para padrinhos, mas entre os homens recém-chegados. Quanto às madrinhas temos três casos de escravas amadrinhando, duas forras e um caso sem a presença de madrinha. As três escravas eram pertencentes ao plantel de Antônio Ramos, sendo escolhidas para tanto as escravas Josefa, Maria e Inácia, sendo que estas duas últimas também desempenharam o papel de madrinha neste plantel entre os homens recém-chegados. No caso das forras, temos mais uma vez Joana Marques amadrinhado neste plantel, só que agora uma mulher escrava adulta e Ana Maria da Conceição o fazendo pela primeira vez.

Ao observarmos a rede parental fictícia dos escravos adultos de Antônio Ramos dos Reis, tanto os homens quanto as mulheres, fica claro que, na sua grande maioria, outros cativos assumiram ou receberam um papel importante na integração dos africanos(as) recém-chegados(as). Autores têm apontado que cativos não nascidos em solo americano aprenderam a se mover nas sociedades do Antigo Regime e estabeleceram formas de organização, de socialização e de proteção já nos primeiros meses de chegada à nova terra. Conforme apontado por Moacir Maia, a cerimônia do batismo não acontecia logo que os cativos chegavam a seu destino e, durante o período de preparação para receber o sacramento, ocorria o contato com parceiros e com muitos outros escravos e libertos (MAIA, 2007, p. 41). Cacilda Machado ressalta que, em grandes escravarias, o percentual de escravos apadrinhando escravos era bem mais significativo. Nesses casos o compadrio era uma 
das formas de incorporar os africanos recém-chegados, e de proporcionar meios de socialização de modo a formar uma comunidade escrava (MACHADO, 2008, p. 176). No entanto, o caráter hierárquico não estava necessariamente ausente no compadrio entre cativos, pois em geral os escravos domésticos ou os que possuíam algum tipo de qualificação profissional apadrinhavam mais do que os escravos de roça.

A escravaria do mestre de campo Antônio Ramos dos Reis evidencia como a teia parental fictícia dos cativos, no caso de adultos recém-chegados, podia servir, em meio a um plantel em permanente processo de renovação, como um mecanismo de integração e sociabilidade. Como o objetivo do trabalho é investigar as redes clientelares feitas pelas escravas e forras, através do amadrinhamento, com os cativos (adultos e crianças) enfocaremos os dados referentes as madrinhas na amostragem retirada do plantel do Antônio Ramos. Como observado, as madrinhas eram repetidas em alguns casos fazendo com que, não só a madrinha, mas também seus afilhados antigos incorporassem em suas teias os recém-chegados a fim de lhes darem um mínimo de segurança, estabilidade e lhes apresentarem os códigos da hierarquia em que viveriam, visto que seriam também seus parentes e aliados.

Por outro lado, via compadrio, conseguimos perceber a possibilidade dessas escravas madrinhas criarem uma rede de alianças que crescia e se reforçava sempre que nova leva de africanos (estrangeiros) chegava neste plantel via tráfico Atlântico. Talvez as cativas que eram recorrentemente chamadas para amadrinhar, criavam uma rede própria de proteção em meio às incertezas da escravidão(FRAGOSO, 2014b, p. 35). Além disso, o fato de os escravos(as) de uma mesma senzala criarem relações de compadrio dava-lhes o sentimento de compartilhar laços em comum, algo fundamental para quem tinha sido desterrado, como os africanos. Em razão de tais compromissos ocorrerem em uma propriedade, ou sob a tutela dos mesmos senhores, eram construídos sob o signo do que recentemente autores têm denominado de casa. A casa era o primeiro e mais universal corpo social com um regime de governo próprio, o grau mais baixo de poder originário, que descansava na desigualdade dos seus membros e seguia as regas do senhor(BEUNZA, 1996, p. 20-32). Para Nuno Gonçalo Monteiro, a casa correspondia a um conjunto coerente de bens simbólicos e materiais, a cuja reprodução alargada estavam obrigados todos os que nela nasciam ou dela dependiam (MONTEIRO, 2011, p. 137). Configurava-se assim como um dos mais importantes vínculos estabelecidos na legitimação das redes de poder no Antigo Regime. Nesse sentido, casa é aqui entendida em sentido amplo. No contexto da América portuguesa, o gerenciamento desta abarcava variada gama de ações por parte das elites, a saber, como conduziam os negócios, como acertavam os enlaces matrimoniais de seus filhos e aparentados, como estabeleciam relações de compadrio com seus amigos e clientes e como se relacionavam com seus escravos e "administrados". Estamos falando de uma realidade moldada por uma concepção corporativa da sociedade, onde as hierarquias eram devidamente naturalizadas e onde a instituição de um pacto desigual entre senhores e subalternos, pelo qual aos primeiros cabia proteção e direção, e aos segundos obediência, e era algo aceitável e mesmo buscado. Sobre tal pacto tinha-se um dos alicerces da casa (FRAGOSO; GUEDES; KRAUSE, 2013, p. 49-50).

Talvez possamos sugerir através da análise da rede parental fictícia dos escravos(as) recém-chegados do plantel de Antônio Ramos dos Reis, no que tange à atuação de madrinhas cativas, que estas conseguiam construir redes clientelares com a escravaria e com este membro da elite local por meio do compadrio e assim adquirir prestígio perante os grupos envolvidos nessas interaçôes. A presença de níveis de hierarquia entre cativos é um ponto já destacado por alguns autores na historiografia ${ }^{13}$ e pode esclarecer como as redes clientelares eram moldadas e davam aos cativos 
chances de melhor posicionamento social. Não seria impreciso argumentar que deviam existir escravas com mais destaque no plantel e que essas podiam ser escolhidas recorrentemente para desempenhar o papel de madrinha e, portanto, de aliada, entre cativos estrangeiros. No plantel de Antônio Ramos dos Reis vimos que algumas escravas foram escolhidas mais de uma vez para amadrinhar escravos adultos recém-chegados, sejam homens ou mulheres, tais como as escravas Domingas, Joanna e Gracia Ramos. Mesmo não tendo como afirmar que tais cativas, que foram as escolhas mais recorrentes no plantel do referido mestre de campo, tinham grande prestígio, não podemos negar que alguma importância deviam ter no interior da senzala para serem tantas vezes escolhidas. O caso de Gracia Ramos evidencia outro dado importante. Analisando alguns dos registros de batismo, percebemos que várias das escravas de Antônio Ramos, que foram escolhidas para desempenhar o papel de madrinhas neste plantel, adotaram o apelido de seu senhor. Além de Gracia Ramos, temos Sebastiana Ramos e Mariana Ramos, bem como as forras Maria Gomes Ramos e Micaela Ramos que foram escravas do referido mestre de campo.

Conforme João Fragoso, Roberto Guedes e Thiago Krause, assumir o nome do senhor não era pouca coisa. Como afirma Russell-Wood (apud FRAGOSO; GUEDES; KRAUSE, 2013, p. 144-145):

Ser capaz de escolher o próprio sobrenome impóe à pessoa que faz a escolha um substancial fardo psicológico e emocional. Indica, por exemplo, valores, prioridades e desejos, como um africano ou afro-brasileiro, escravo, alforriado ou nascido livre, via a si mesmo e como era a identidade que desejava que os outros os reconhecessem.

Não podemos desconsiderar que os cativos também eram movidos por interesses pessoais em jogo. Escravos e senhores faziam leituras diferenciadas dos códigos paternalistas e clientelares que permeavam as regras do cativeiro tecidas por ambos. Muito provavelmente, as escravas mais vezes escolhidas para amadrinhar os adultos recém-chegados e as que possuíam o apelido de seu senhor pertenciam a uma rede social de aliados que envolvia diferentes estratos sociais: escravos, forros e livres. Provavelmente tal rede servia de base clientelar para a ação do mestre de campo Antônio Ramos dos Reis, ou seja, para o seu mando na localidade. Porém, também provavelmente, tal clientela ou rede de amizades hierarquizada fazia parte das estratégias de vida das cativas mencionadas. Sabemos, por exemplo, pelo testamento deixado pelo referido poderoso local, datado de 1761, que a parda Micaela Ramos (escolhida para ser madrinha de uma criança cativa pertencente a Antônio Ramos) foi alforriada pelo seu senhor pelo menos antes de 1742, já que nesta data ela aparece como forra e proprietária da escrava Mariana, que amadrinhou um escravo adulto e um rebento do plantel do dito mestre de campo. Além disso, conforme Antônio Ramos assinala em testamento, Micaela ganhou, juntamente com a liberdade, uma morada de casas. Tais dados indicam que ao ser alforriada Micaela não deixou de se ligar a seu antigo senhor, o que é evidenciado pela adoção de seu apelido e pelo fato de continuar habitando próximo a ele, já que a morada de casas que ganhou ficava próxima a morada de casas onde Antônio Ramos vivia em Ouro Preto. Nesta propriedade a forra Micaela morou até seu falecimento. Tal moradia foi posteriormente passada para outra escrava de Antônio Ramos, Anna Ramos, e seus dois filhos Pedro e Paulo, conforme estipulado em seu testamento, momento no qual também passou carta de alforria para tais escravos. Pelo seu testamento sabemos ainda que Sebastiana Ramos, preta de nação coura (que amadrinhou em 1746 um escravo de 15 anos recém-chegado ao plantel deste poderoso local), e seus 
dois filhos, Izidoro e Antônio pardo, ganharam alforria e uma morada de casas, também próximo à propriedade em que Antônio Ramos vivia ${ }^{14}$.

Percebe-se que algumas escravas do mestre de campo, que possuíam seu apelido, ganharam alforrias, propriedades e batizaram escravos de seu senhor, servindo assim como instrumentos na cadeia de autoridade cuja referência era o poderoso local em foco. Provavelmente tais escravas, entre outras(os) que também apareceram em seu testamento com as mesmas regalias, conseguiram-nas como resultado de uma série de estratégias ou de relações pessoais, horizontais e verticais, nas quais reconheciam a autoridade de Antônio Ramos, evidenciado em seu nome. Pelo testamento fica explícito que algumas cativas e ex-cativas de Antônio Ramos, madrinhas em seu plantel, ganharam alforrias para filhos e moradas de casas, práticas que revelam traços da rede clientelar em que ele, seus cativos, e também mulheres forras, se envolviam.

Não eram todas as escravas que conseguiam suas alforrias, moradas de casas, e que eram escolhidas para ser madrinhas de escravos do plantel. Ao conseguirem posição diferenciada e prestígio, algumas cativas criavam suas próprias redes sociais. Acumulavam, assim, recursos ou um portfólio de amizades entre escravos e forros com os quais se tornavam peças vitais para o funcionamento dessa economia escravista, cuja base era as relações pessoais. Ou seja, aquelas madrinhas cativas não eram apenas marionetes de seus senhores, mas capazes de organizar suas próprias malhas de amizades, jogar com os senhores e adquirir novas posições na hierarquia social costumeira. Por essa razão, todos os grupos tinham que marcar e reiterar as desigualdades ou mesmo produzir novos índices de diferenciação (FRAGOSO, 2014a, p. 271).

Temos assim, no plantel de Antônio Ramos, diversas relações pessoais entre distintos estratos sociais, todos submetidos ao mando de um único senhor capaz de influenciar a vida dos moradores de sua casa, concedendo-lhes ou retirando-lhes, por exemplo, liberdade, propriedades (FRAGOSO, 2009, p. 192). Tratava-se de uma reciprocidade entre desiguais e, ainda que houvesse tensões, era uma troca justa, pois, em sociedades escravistas de Antigo Regime, a noção de justiça era equitativa: a cada um conforme o seu lugar na hierarquia social (FRAGOSO, 2009, p. 157). Obviamente que o reconhecimento de solidariedade vertical, não significava ausência de conflitos entre eles e seus proprietários (SOARES, 2006, p. 207-208).

O batismo das crianças escravas pertencentes ao plantel de Antônio Ramos também corrobora muitos dos argumentos anteriormente expostos. Como já indicado mais acima, o dito mestre de campo levou a pia batismal, como proprietário, 27 crianças escravas entre 1727 e 1748 em Vila Rica. Destas crianças, 3 eram fruto de uniôes legítimas, as demais tinham pais incógnitos ou não mencionados nos registros. 
Tabela 3 - Padrinhos e madrinhas das crianças escravas do mestre de campo Antônio Ramos dos Reis, $1727-1748$

\begin{tabular}{|c|c|c|c|c|c|c|c|c|c|c|}
\hline & \multicolumn{2}{|c|}{ Escravos } & \multicolumn{2}{c|}{ Livres } & \multicolumn{2}{c|}{ Forros } & \multicolumn{2}{c|}{ Sem informação } & \multicolumn{3}{c|}{ Total } \\
\cline { 2 - 12 } & $\#$ & $\%$ & $\#$ & $\%$ & $\#$ & $\%$ & $\#$ & $\%$ & $\#$ & $\%$ \\
\hline Padrinhos & 13 & 48,15 & 12 & 44,44 & 1 & 3,70 & 1 & 3,70 & 27 & 100 \\
\hline Madrinhas & 11 & 40,74 & - & - & 13 & 48,15 & 3 & 11,11 & 27 & 100 \\
\hline
\end{tabular}

Fonte: Arquivo Eclesiástico da Arquidiocese de Mariana (AEAM): Livros de batismos de escravos de Mariana e seu termo. Registros Paroquiais de Batismos, livros 0-03 e T-01. Arquivo da Casa dos Contos (ACC): Registros Paroquiais de Batismos, rolo 027, volume 491 e 493; rolo 104, volume 492, período de 1711 a 1750.

Com relação à escolha do padrinho, em 13 casos os pais, ou a mãe, como fora na maioria dos registros ora analisados, optaram por entregar seus rebentos a padrinhos escravos, sendo que 7 tinham como proprietário o próprio Antônio Ramos dos Reis e 6 pertenciam a outros senhores. Entre tais senhores, três escravos de Antônio Simões foram padrinhos neste plantel, assim como um escravo do coronel Manoel Ferreira Agrelos, um escravo do feitor de Antônio Ramos dos Reis e um escravo da forra Joana Marques que, como se verá, será escolhida para amadrinhar filhos de escravos desse poderoso por diversas vezes. Dos escravos de seu plantel escolhidos para serem padrinhos das crianças, temos o cativo Francisco fazendo-o por duas vezes e os escravos Bento, Gregório, Leandro, Salvador e Mathias Ramos fazendo-o uma vez.

Tivemos ainda 12 homens livres apadrinhando os inocentes do plantel de Antônio Ramos. Destes, Jerônimo de Souza Lobo, Manoel da Costa Barbosa, Francisco Martins e Fernando Gonçalves Pereira, este último morador na freguesia de São Bartolomeu, fizeram-no por duas vezes. Domingos da Costa, sacristão da Igreja Matriz de Vila Rica, Antônio Gonçalves Machado, Custódio Alves e Manuel dos Santos apadrinharam uma vez no plantel de Antônio Ramos. Temos ainda um pardo forro, chamado Antônio Lopes de Oliveira, sendo padrinho de um rebento do plantel do dito mestre de campo. Por fim, tivemos um caso em que não consegui identificar a condição jurídica do padrinho.

Este quadro indica que no caso do batismo das crianças escravas, seus pais, não mais estrangeiros, provavelmente com conhecimento mais profundo acerca das regras costumeiras locais, com formação de laços antigos de amizade e solidariedade, diversificaram a escolha dos padrinhos de seus filhos estabelecendo formas de organização social e parental mais complexas. Além de escravos que podiam ter uma ascendência sobre os demais no plantel de Antônio Ramos e que já haviam sido escolhidos como padrinhos de escravos adultos recém-chegados (caso de Francisco, Bento e Salvador) bem como de Mathias Ramos cujo apelido sugere uma posição diferenciada, as mães escravas também escolheram como padrinhos de seus filhos escravos de autoridades locais como o do coronel Manoel Ferreira Agrelos e de sujeitos com poder e destaque na propriedade do mestre de campo, caso do cativo do feitor. Temos ainda homens livres apadrinhando filhos de escravas, denotando assim que usavam o compadrio como forma de integração social, isto é, mecanismo a ligar institucionalmente cativos e livres. O compadrio efetuado por pessoas de outro estatuto, no caso por livres, pode ser revelador também dos elos que mantinham a casa, pois, ao que parece, na escravaria de Antônio Ramos, os livres que apadrinharam se repetiam com frequência. Dos 12 padrinhos livres temos Manuel da Costa Barbosa, Fernando Gonçalves Pereira, Jeronimo de Souza Lobo, Francisco Martins fazendo-o por duas vezes, sendo que este último era morador nas terras de 
Antônio Ramos. Temos ainda Domingos da Costa, sacristão da igreja matiz de Vila Rica, Antônio Gonçalves Machado, Manoel dos Santos e Custódio Alves fazendo-o uma vez. Parece tratar-se de indivíduos de estatuto diferente, porém pertencentes à mesma casa, que apadrinhavam cativos na escravaria de Antônio Ramos, ligando-se pelo parentesco ritual a ela (FRAGOSO, 2010, p. 276).

A rede parental construída pelos(as) cativos(as) de Antônio Ramos dos Reis acerca das madrinhas de crianças escravas é muito interessante e revela as estratégias que muitas vezes os pais lançavam mão para aumentarem as chances de seus filhos serem beneficiados por tais contatos. Não por acaso, 13 das 27 madrinhas eram forras. Destas, a forra Joana Marques amadrinhou nada menos que seis crianças neste plantel, e uma escrava sua, chamada Domingas Marques, amadrinhou três crianças cativas de Antônio Ramos. Vale lembrar que, como visto anteriormente, Joana Marques batizou também seis cativos adultos ${ }^{15}$. Ou seja, ela tinha contato com pelo menos 12 escravos deste plantel mediante o batismo de inocentes e adultos, todos imersos em sua rede de relações. Temos ainda as forras Maria Fernandes, Joanna, Maria, Joanna de Assunção, Plácida Pereira, Maria Gomes Ramos e a parda forra Micaela Ramos sendo escolhidas como madrinhas dos filhos de escravas pertencentes ao mestre de campo em destaque. Esta última forra, Micaela Ramos, além de ser ela própria escolhida como madrinha de um rebento, teve também uma escrava sua, Mariana, amadrinhando uma criança do plantel de Antônio Ramos (lembrando que esta mesma cativa havia sido escolhida para ser madrinha de um adulto recém-chegado a escravaria do mestre de campo). Ou seja, mais um caso de forra que se ligou pelo compadrio aos escravos deste poderoso local não só através de si mesma, mas de uma escava sua ${ }^{16}$. Dentre as 11 madrinhas escravas, 6 eram pertencentes ao dito poderoso e 5 a senhores diferentes. Das que pertenciam a outros donos temos as já mencionadas cativas de Joana Marques e Micaela Ramos que juntas amadrinharam quatro vezes e uma escrava chamada Rosa pertencente a Manoel de Távora. As que pertenciam a Antônio Ramos se denominavam Quitéria, Inácia, Rosa, Luiza, Domingas e Sebastiana. Por fim, tivemos três madrinhas que não conseguimos saber sua condição jurídica ${ }^{17}$. Portanto, na grande maioria dos casos, as madrinhas deste plantel, quando não eram forras, eram cativas pertencentes ou a essas forras ou ao próprio Antônio Ramos dos Reis.

Joana Marques deve ter sido uma mulher com algum recurso, prova-o a escrava que possuía, Domingas Marques, que apareceu nos registros amadrinhando três vezes, além de portar seu apelido, bem como o prestígio para ser tantas vezes escolhida para amadrinhar adultos e filhos de escravas de Antônio Ramos, devendo ter com este também uma boa relação, fenômeno que demonstrava o respeito da senzala a ela. A história dessa forra indica que era possível a indivíduos pertencentes ao grupo dos subalternos utilizar as relaçôes pessoais como recurso para viver e progredir no cenário escravista (FRAGOSO, 2014b, p. 81; p. 97).

Outro exemplo digno de nota é o da já mencionada parda forra Micaela Ramos. Ela amadrinhou uma criança no plantel de Antônio Ramos e sua escrava, Mariana, amadrinhou uma criança e um adulto no plantel do mestre de campo. Ou seja, pelo batismo no qual participou, bem como os realizados por sua escrava, essa parda forra se ligava a três cativos da escravaria do referido mestre de campo. Além do apelido, as relaçóes de reciprocidade entre Antônio Ramos e Micaela podem ser visualizadas também no testamento do primeiro, já que, como mencionado anteriormente, através dele sabemos que Micaela havia sido escrava do mestre de campo sendo, posteriormente, alforriada, vivendo em uma morada de casas dada por Antônio Ramos. Com isso, tinha uma condição de vida relativamente confortável a ponto de ter se tornado também 
proprietária de cativos. Desta forma, nota-se que as mães cativas do plantel do referido potentado procuraram escolher madrinhas que pudessem ter algum recurso e boas relaçóes com seu senhor, aumentando assim as possibilidades de talvez, no futuro, seus filhos serem beneficiados de alguma forma. Parece que todos esses cabedais (apelido, alforria, terras, esmolas, compadrio) identificavam os indivíduos denominados de subalternos, revelavam suas histórias e formavam um cabedal de relações sociais que serviam de critérios para a estratificação nas senzalas e diante da sociedade em que se inseriam. Como tal, esse cabedal se traduzia na possibilidade de alianças, via compadrio, com escravos, forros, livres, senhores, como o exemplo de Micaela Ramos, Anna Ramos, Sebastiana Ramos e Joana Marques o demonstraram.

Por meio do sacramento do batismo, essas mulheres confirmavam alianças com outras famílias escravas e, de certa forma, com o senhor delas. Através da proximidade com Antônio Ramos e da formação de redes clientelares com ele, cujo indício buscamos nos amadrinhamentos constantes, nos legados deixados para elas em testamento, no apelido que portavam, escravas e forras construíam redes de alianças no interior das senzalas. Ligavam, assim, esta à casa nobre, o que aos olhos das mães, pais e adultos recém-chegados devia ser extremamente vantajoso. As práticas de compadrio, e com elas a ideia de casa, podem ser encaradas como fundamentais para os poderosos locais das Minas do ouro, pois davam recursos e suporte para a construção de redes de relações entre elite e subalternos.

\section{Referências}

ALMEIDA, Carla Maria de Carvalho de. Homens ricos, homens bons: produção e hierarquização social em Minas colonial, 1750-1822. 2001. Tese (Doutorado em História) - Instituto de Ciências Humanas e Filosofia, Universidade Federal Fluminense, Niterói, 2001.

BEUNZA, José María Imízcoz. Comunidad, red social y élites: un análisis de la vertebración social en el Antiguo Régimen. In: BEUNZA, José María Imízcoz (org.). Elites, poder y red social: las élites del País Vasco y Navarra en la Edad Moderna. Bilbao: Universidad del País Vasco, 1996.

BRÜGGER, Silva Maria Jardim. Minas Patriarcal: família e sociedade (São João Del Rei - Séculos XVIII e XIX). São Paulo: Annablume, 2007.

ENGEMANN, Carlos. Da comunidade escrava e suas possibilidades, séculos XVII-XIX. In: FLORENTINO, Manolo (org.). Tráfico, cativeiro e liberdade: Rio de Janeiro, séculos XVII-XIX. Rio de Janeiro: Civilização Brasileira, 2005.

FARIA, Sheila de Castro. Francisca Maria Teresa e as sinhás pretas no Brasil colonial. In: VAINFAS, Ronaldo; SANTOS, Georgina; NEVES, Guilherme Pereira das. Retratos do Império: trajetórias individuais no mundo português nos séculos XVI a XIX. Niterói: Eduff, 2006.

FIGUEIREDO, Luciano. O avesso da memória: cotidiano e trabalho da mulher em Minas Gerais no século XVIII. Rio de Janeiro: José Olympio; Brasília: Edunb, 1993.

FIGUEIREDO, Luciano. Mulheres nas Minas Gerais. In: PRIORE, Mary Del (org.). História das mulheres no Brasil. 2. ed. São Paulo: Contexto, 1997.

FLORENTINO, Manolo; GÓES, José Roberto. A paz das senzalas: famílias escravas e tráfico atlântico, Rio de Janeiro c. 1790 - c. 1850. Rio de Janeiro: Civilização Brasileira, 1997.

FRAGOSO, João. Alternativas metodológicas para a história econômica e social: micro-história italiana, Fredrik Barth e a história econômica colonial. In: ALMEIDA, Carla Maria Carvalho de; OLIVEIRA, Mônica Ribeiro de (org.). Nomes e números: alternativas metodológicas para a história econômica e social. Juiz de Fora: Editora UFJF, 2006. 
FRAGOSO, João. O capitão João Pereira Lemos e a parda Maria Sampaio: notas sobre hierarquias rurais costumeiras no Rio de Janeiro do século XVIII. In: ALMEIDA, Carla Maria Carvalho de; OLIVEIRA, Mônica Ribeiro de (org.). Exercícios de micro-história. Rio de Janeiro: FGV, 2009.

FRAGOSO, João. Capitão Manuel Pimenta Sampaio, senhor do engenho do Rio Grande, neto de conquistadores e compadre de João Soares, pardo: notas sobre uma hierarquia social costumeira (Rio de Janeiro, 1700-1760). In: FRAGOSO, João; GOUVÊA, Maria de Fátima (org.). Na trama das redes: política e negócios no império português, séculos XVI a XVIII. Rio de Janeiro: Civilização Brasileira, 2010.

FRAGOSO, João; GUEDES, Roberto; KRAUSE, Thiago (org.). A América portuguesa e os sistemas atlânticos na Época Moderna. Rio de Janeiro: FGV, 2013.

FRAGOSO, João. Elite das senzalas e nobreza da terra numa sociedade rural do Antigo Regime nos trópicos: Campo Grande (Rio de Janeiro), 1704-1741. In: FRAGOSO, João; GOUVÊA, Maria de Fátima (org.). O Brasil colonial 1720-1821. v. 3. Rio de Janeiro: Civilização Brasileira, 2014a.

FRAGOSO, João; GUEDES, Roberto; SAMPAIO, Antônio Carlos Jucá de (org.). Arquivos paroquiais e história social na América Lusa, séculos XVII e XVIII: métodos e técnicas de pesquisa na reinvenção de um corpus documental. Rio de Janeiro: Mauad X, 2014.

FRAGOSO, João. Apontamentos para uma metodologia em História Social a partir de assentos paroquiais (Rio de Janeiro, séculos XVII e XVIII). In: FRAGOSO, João; GUEDES, Roberto; SAMPAIO, Antônio Carlos Jucá de (org.). Arquivos paroquiais e história social na América Lusa, séculos XVII e XVIII: métodos e técnicas de pesquisa na reinvenção de um corpus documental. Rio de Janeiro: Mauad X, 2014b.

FRANCO, Francisco de Assis Carvalho. Dicionário de Bandeirantes e Sertanistas do Brasil. Belo Horizonte: Itatiaia; São Paulo: USP, 1989.

FREIRE, Jonis. Compadrio em uma freguesia escravista: Senhor Bom Jesus do Rio Pardo (MG) (1838-1888). In: ENCONTRO NACIONAL DE ESTUDOS POPULACIONAIS, 14., 2004, Caxambu. Anais [...].Caxambu: ABEP, 2004.

FURTADO, Júnia Ferreira. Pérolas negras: mulheres livres de cor no Distrito Diamantino. In: FURTADO, Júnia Ferreira (org.). Diálogos oceânicos: Minas Gerais e as novas abordagens para uma história do Império ultramarino português. Belo Horizonte: UFMG, 2001.

FURTADO, Júnia Ferreira. Chica da Silva e o Contratador de Diamantes: o outro lado do mito. São Paulo: Companhia das Letras, 2003.

GUDEMAN, Stephen; SCHWARTZ, Stuart B. Purgando o pecado original: compadrio e batismo de escravos na Bahia no século XVIII. In: REIS, João José (org.). Escravidão e invenção da liberdade: estudos sobre o negro no Brasil. São Paulo: Brasiliense, 1988.

GUEDES, Roberto; SOARES, Márcio de Sousa. Tensões, comportamentos, e hábitos de consumo na sociedade senhorial da América portuguesa. In: FRAGOSO, João; GOUVÊA, Maria de Fátima (org.). O Brasil colonial 1720-1821. v. 3. Rio de Janeiro: Civilização Brasileira, 2014.

HAMEISTER, Martha Daisson. Para dar calor à nova povoação: estudo sobre estratégias sociais familiares a partir de registros batismais da Vila do Rio Grande (1738-1763). 2006. Tese (Doutorado em História) Universidade Federal do Rio de Janeiro, Rio de Janeiro, 2006.

HESPANHA, António Manuel; XAVIER, Ângela Barreto. As Redes Clientelares. In: HESPANHA, António Manuel (org.). História de Portugal: o Antigo Regime. v. 4. Lisboa: Estampa, 1998.

KRAUSE, Thiago. Compadrio e escravidão na Bahia seiscentista. In: FRAGOSO, João; GUEDES, Roberto; SAMPAIO, Antônio Carlos Jucá de (org.). Arquivos Paroquiais e História Social na América Lusa, séculos XVII e XVIII: métodos e técnicas de pesquisa na reinvenção de um corpus documental. 1. ed. Rio de Janeiro: Mauad X, 2014.

LARA, Sílvia Hunold. Campos da Violência: escravos e senhores na Capitania do Rio de Janeiro, 1750-1808. Rio de Janeiro: Paz e Terra, 1988.

LIMA, Carlos. Escravos de Peleja: a instrumentalização da violência escrava na América portuguesa (1580-1850). Revista de Sociologia e Política, Curitiba, n. 18, p. 131-152, jun. 2002.

MACHADO, Cacilda. As muitas faces do compadrio de escravos: o caso da freguesia de São José dos Pinhais (PR), na passagem do século XVIII para o XIX. Revista Brasileira de História, São Paulo, v. 26, n. 52, p. 49-77, 2006.

MACHADO, Cacilda. A trama das vontades: negros, pardos e brancos na produção da hierarquia social do Brasil escravista. Rio de Janeiro: Apicuri, 2008. 
MAIA, Moacir Rodrigo de Castro. O apadrinhamento de africanos em Minas Colonial: o (re)encontro na América (Mariana, 1715-1750). Revista Afro-Ásia, Salvador, n. 36, p. 39-80, 2007.

MAIA, Moacir Rodrigo de Castro. As relações de parentesco ritual em uma sociedade escravista: compadres, padrinhos e afilhados no cotidiano mineiro da primeira metade do século XVIII. In: SEMINÁRIO SOBRE ECONOMIA MINEIRA, 18., 2008, Belo Horizonte. Anais [...]. Belo Horizonte: Cedeplar-UFMG, 2008.

MONTEIRO, Nuno Gonçalo. As famílias, os indivíduos: casa, casamento e nome. In: MATTOSO, José (org.). História da vida privada em Portugal: a Idade Moderna. Lisboa: Círculo de Leitores; Temas e Debates, 2011.

PAIVA, Eduardo França. Escravos e libertos nas Minas Gerais do século XVIII: estratégias de resistência através dos testamentos. 2. ed. São Paulo: Annablume, 2000.

PAIVA, Eduardo França. Escravidão e universo cultural na colônia: Minas Gerais, 1716-1789. Belo Horizonte: EDUFMG, 2001

PAIVA, Eduardo França. Bateias, carumbés, tabuleiros: mineração africana e mestiçagem no Novo Mundo. In: PAIVA, Eduardo França; ANASTASIA, Carla Maria Junho (org.). O trabalho mestiço: maneiras de pensar e formas de viver, séculos XVI a XIX. São Paulo: Annablume; Belo Horizonte: PPGH-UFMG, 2002.

PRIORE, Mary Del. A mulher na história do Brasil. São Paulo: Contexto, 1989.

RAMOS, Donald. Teias sagradas e profanas: o lugar do batismo e compadrio na sociedade de Vila Rica durante o século do ouro. Varia História, n. 31, jan. 2004.

SOARES, Márcio de Sousa. A remissão do cativeiro: alforrias e liberdades nos Campos dos Goitacazes, c.1750 - c.1830. Tese (Doutorado em História) - Universidade Federal Fluminense, Niterói, 2006.

VENÂNCIO, Renato Pinto. Compadrio e rede familiar entre forras de Vila Rica, 1713-1804. In: JORNADA SETECENTISTA, 5., 2003, Curitiba. Anais [...]. Curitiba: [s.n.], 2003.

\section{Notas}

1. Algumas ideias básicas contidas neste texto foram apresentadas em versão resumida no XIX Encontro Regional de História - Profissão Historiador: formação e mercado de trabalho da Anpuh-MG, ocorrida em Juiz de Fora entre 28 e 31 de julho de 2014, e foram publicadas nos anais do evento.

2. Sobre tais temas ver: PRIORE, Mary Del. A mulher na história do Brasil. São Paulo: Contexto, 1989. FIGUEIREDO, Luciano R. de Almeida. O avesso da memória: cotidiano e trabalho da mulher em Minas Gerais no século XVIII. Rio de Janeiro: José Olympio; Brasília: Edunb, 1993. FIGUEIREDO, Luciano R. de Almeida. Mulheres nas Minas Gerais. In: PRIORE, Mary Del (org.). História das mulheres no Brasil. 2. ed. São Paulo: Contexto, 1997. PAIVA, Eduardo França. Escravos e libertos nas Minas Gerais do século XVIII: estratégias de resistência através dos testamentos. 2. ed. São Paulo: Annablume, 2000. PAIVA, Eduardo França. Escravidão e universo cultural na colônia: Minas Gerais, 1716-1789. Belo Horizonte: EDUFMG, 2001. FURTADO, Júnia Ferreira. Pérolas negras: mulheres livres de cor no Distrito Diamantino. In: FURTADO, Júnia Ferreira (org.). Diálogos oceânicos: Minas Gerais e as novas abordagens para uma história do Império ultramarino português. Belo Horizonte: Editora UFMG, 2001. FURTADO, Júnia Ferreira. Chica da Silva e o Contratador de Diamantes: o outro lado do mito. São Paulo: Companhia das Letras, 2003. FARIA, Sheila de Castro. Francisca Maria Teresa e as sinhás pretas no Brasil colonial. In: VAINFAS, Ronaldo; SANTOS, Georgina; NEVES, Guilherme Pereira das. Retratos do Império: trajetórias individuais no mundo português nos séculos XVI a XIX. Niterói: Eduff, 2006.

3. Cf. nota 1.

4. Cf. FRAGOSO; GUEDES; SAMPAIO, 2014a.

5. Ver: MACHADO, Cacilda. A trama das vontades: negros, pardos e brancos na produção da hierarquia social do Brasil escravista. Rio de Janeiro: Apicuri, 2008. FRAGOSO, João. Alternativas metodológicas para a história econômica e social: micro-história italiana, Fredrik Barth e a história econômica colonial. In: ALMEIDA, Carla Maria Carvalho de; OLIVEIRA, Mônica Ribeiro de (org.). Nomes e números: alternativas metodológicas para a história econômica e social. Juiz de Fora: Editora UFJF, 2006. FRAGOSO, João. Capitão Manuel Pimenta Sampaio senhor do engenho do Rio Grande, neto de conquistadores e compadre de João Soares, pardo: notas sobre uma hierarquia social costumeira (Rio de Janeiro, 1700-1760). In: FRAGOSO, João; GOUVEIA, Maria de Fátima (org.). Na trama das redes: política e negócios no império português, séculos XVI e XVIII. Rio de Janeiro: Civilização Brasileira, 2010. FRAGOSO, João. Elite das senzalas e nobreza principal da terra numa sociedade rural de Antigo Regime nos trópicos. Campo Grande (Rio de janeiro), 1704-1740. In: FRAGOSO, João; 
GOUVEIA, Maria de Fátima (org.). O Brasil colonial, 1580-1720. Rio de Janeiro: Civilização Brasileira, 2014a. FRAGOSO, João. Apontamentos para uma metodologia em história social a partir de assentos paroquiais (Rio de Janeiro, séculos XVII e XVIII). In: FRAGOSO, João; GUEDES, Roberto; SAMPAIO, Antônio Carlos Jucá de (org.). Arquivos paroquiais e história social na América Lusa, séculos XVII e XVIII: métodos e técnicas de pesquisa na reinvenção de um corpus documental. Rio de Janeiro: Mauad X, 2014. HAMEISTER, Martha Daisson. Para dar calor à nova povoação: estudo sobre estratégias sociais familiares a partir de registros batismais da Vila do Rio Grande (1738-1763). Tese (Doutorado em História) - Universidade Federal do Rio de Janeiro, Rio de Janeiro, 2006.

6. REIS, Antônio Ramos dos. Primeiro Ofício - Testamento do Arquivo Histórico do Museu da Inconfidência. Ouro Preto: Casa do Pilar de Ouro Preto, n. 20, f. 74, 1761.

7. REIS, Antônio Ramos dos [mestre de campo dos Terço das Ordenanças de Vila Rica]. Requerimento solicitando ao mercê de o confirmar na serventia do referido posto. Conselho Ultramarino - Minas Gerais: Arquivo Histórico Ultramarino, cx. 20, doc. 48, [anterior a] 6 fev. 1732. Anexo: carta patente. REIS, Antônio Ramos dos. Requerimento solicitando confirmação da patente de capitão mor das Ordenanças de Vila Rica e seu termo. Conselho Ultramarino - Minas Gerais: Arquivo Histórico Ultramarino, cx. 39, doc. 67, [anterior a] 23 set. 1740. Anexo: carta patente.

8. Memorial Histórico-Político da Câmara Municipal de Ouro Preto. Cor \& Cor Editorial: Ouro Preto, Dezembro de 2004.

9. REIS, Antônio Ramos dos. Requerimento solicitando a D. João V a mercê de o isentar do exercício do ofício de juiz dos Órfãos de Vila Rica, em virtude dos afazeres que tem na sua lavra. Conselho Ultramarino - Minas Gerais: Arquivo Histórico Ultramarino, cx. 22, doc. 52, [anterior a] 17 out. 1732. Anexo: vários documentos.

10. REIS, Antônio Ramos dos [mestre de campo dos Terço das Ordenanças de Vila Rica]. Requerimento pedindo licença para passar ao Reino, a fim de se curar. Conselho Ultramarino - Minas Gerais: Arquivo Histórico Ultramarino, cx. 31, doc. 67, [anterior a] 1736. Anexo: carta patente. REIS, Antônio Ramos dos [capitão mor das Ordenanças de Vila Rica]. Requerimento solicitando que $D$. João $V$ mande declarar quais as honras e o lugar que lhe corresponde em atos públicos e particulares, poro seu cargo não haver sido respeitado na festa realizada para celebrar o nascimento da Infanta. Conselho Ultramarino - Minas Gerais: Arquivo Histórico Ultramarino, cx. 41, doc. 10, [anterior a] 27 jan. 1741. Anexo: requerimentos, certidões.

11. Cf. nota 6.

12. REGISTROS PAROQUIAIS DE BATISMOS. Livros de batismos de escravos de Mariana e seu termo. Mariana: Arquivo Eclesiástico da Arquidiocese de Mariana, livros 0-03 e T-01, período 1711-1750. REGISTROS PAROQUIAIS DE BATISMOS. Livros de batismos de escravos de Ouro Preto e seu termo. Ouro Preto: Arquivo Casa dos Contos, rolo 027, v. 491 e 493 ; rolo 104, v. 492; rolo 027, v. 491, período 1711-1750.

13. Cf. LARA, 1988; LIMA, 2002.

14. Cf. nota 6.

15. Cf. nota 11 .

16. Cf. nota 10.

17. Cf. nota 10.

Data de recebimento: 27/01/2018

Data de aprovação: 30/10/2018 